\title{
Clinical characteristics and laboratory indicator analysis of 69 COVID-19 pneumonia patients in Suzhou, China
}

\section{Yi Wang}

The afflilated infectious hosptal of soochow university

\section{Lin Yao}

the affiliated infectious hospital of soochow university

Jian-Ping Zhang

the affiliated infectous hospital of soochow university

Pei-Jun Tang

the affiliated infectious hospital of soochow university

Zhi-Jian Ye

the affiliated infectious hospital of soochow university

Xing-Hua Shen

the affiliated infectious hospital of soochow university

Jun-Chi Xu ( $\square$ xujunchi19850504@126.com )

https://orcid.org/0000-0002-1447-7593

Mei-Ying Wu

the affiliated infectious hospital of soochow university

Xin $\mathrm{Yu}$

the affiliated infectious hospital of soochow university

\section{Research Article}

Keywords: COVID-19, SARS-CoV-2, FIB, Treatment, Hormone

Posted Date: April 8th, 2020

DOI: https://doi.org/10.21203/rs.3.rs-20968/v1

License: (a) (1) This work is licensed under a Creative Commons Attribution 4.0 International License.

Read Full License 


\section{Abstract}

Background Sudden exacerbations and respiratory failure are major causes for the death of severe COVID-19 pneumonia patient and but now the detection and treatment of severe patients is still lack.

Methods A retrospective analysis is conducted on 69 collected cases, which are about 69 patients with COVID-19 pneumonia who were admitted to the Suzhou Fifth People's Hospital from January 1, 2020 to February 8,2020 . Their epidemiological, clinical and imaging characteristics as well as laboratory data of the 69 patients were analyzed.

Results The study found fibrinogen increased in $45(65.2 \%)$ patients and when the fibrinogen takes a critical value of $4.805 \mathrm{~g} / \mathrm{L}$, the sensitivity and specificity, helping distinguish general and severe classification, are $100 \%$ and $14 \%$, respectively, which are significantly better than lymphocyte and myoglobin. Chest CT images indicate that the cumulative number of lung lobes in severe patients were significantly higher than that in general patients $(\mathrm{P} \otimes 0.05)$ and the cumulative number of lung lobes in the lesions was negatively correlated with lymphocyte, and positively correlated with myoglobin and fibrinogen. Our study also found that there is no obvious effect of hormone therapy in severe patients with COVID-19.

Conclusions Based on the retrospective analysis, the fibrinogen were found increased in severe patients and were better than lymphocyte and myoglobin in respect of distinguishing general and severe patients. And the study also suggested hormone treatment has no significant effect on COVID-19.

\section{Background}

Novel coronavirus pneumonia is an acute infectious disease caused by syndrome coronavirus 2 (SARSCoV-2) infection and mainly transmitted by respiratory tract ${ }^{[1]}$. Since the first novel coronavirus pneumonia case was reported in Wuhan, China, the new coronavirus spread rapidly across the country, it is also endemic in many countries around the world, including Japan, Singapore, Thailand and the United States ${ }^{[2]}$. Thus far thousands of cases have been confirmed. On February 11, 2020, World Health Organization (WHO) officially announced that the cause of the new coronavirus pneumonia is a variant new coronavirus, and named the disease which it caused as coronavirus disease 2019 (COVID-19). On February 8, 2020, National Health Commission of China temporarily named the pneumonia caused by the new coronavirus as the new coronavirus pneumonia (NCP).

SARS-CoV-2 is a coronavirus belonging to the genus $\beta$, with an envelope, particles that are round or oval, often polymorphic with a diameter of $60-140 \mathrm{~nm}$. Its genetic characteristics are obviously different from those of SARSr-CoV and MERSr-CoV ${ }^{[3]}$. Current research shows that it has more than $85 \%$ homology with bat SARS-like coronavirus (bat-SL-CoVZC45) ${ }^{[4]}$. When isolated and cultured in vitro, SARS-CoV-2 can be found in human respiratory epithelial cells in about 96 hours, while it takes about 6 days to isolate and culture in VeroE6 and Huh-7 cell lines. So far, we are not fully aware of the pathogenesis of the COVID-19 pneumonia, its development process in the body, and its route of transmission. The gold standard for the 
diagnosis is real-time fluorescence RT-PCR for nucleic acid positive SARS-CoV-2, but this method is timeconsuming and has the possibility of false negative. Understanding the early epidemiological and clinical characteristics of COVID-19 pneumonia patients is extremely important for diagnosis, so we conducted a retrospective analysis on 69 cases of COVID-19 pneumonia.

\section{Methods}

\section{Patients}

A total of 69 cases were collected, which are about 69 patients with COVID-19 pneumonia who were admitted to the Pulmonary Department Building A of Suzhou Fifth People's Hospital from January 1 , 2020 to February 8, 2020 (The diagnosis conforms to the diagnostic criteria (NHC Diagnostic Criteria (V5)) set out in the Diagnosis and Treatment of Pneumonia Infected by Novel Coronavirus (5th trial edition) issued by the General Office of the National Health Commission on February 4, 2020). According to the NHC Diagnostic Criteria (V5), 2 cases were classified as mild group, 49 cases as general group, 16 cases as severe group, and 2 cases of fatal group. Due to the limited sample size and in order to reduce the result error, we combine the mild group and general group into Group A, and combine the sever group and fatal group to Group B. We also selected 20 healthy people from the physical examination center of our hospital as the control group. The study has obtained the informed consent and the approval of the Ethics Committee of Suzhou Fifth People's Hospital.

\section{Study inclusion criteria}

The diagnosis of the COVID-19 pneumonia manifests with chest CT imaging abnormalities, even in asymptomatic patients, with rapid evolution from focal unilateral to diffuse bilateral ground-glass opacities that progressed to or co-existed with consolidations within 1-3 weeks. Combining assessment of imaging features with clinical and laboratory findings could facilitate early diagnosis of COVID-19 pneumonia. conforms to the NHC Diagnostic Criteria (V5), which set out as: Mild type: clinical symptoms are mild and no pneumonia on imaging;General type: with fever, respiratory tract and other symptoms, imaging shows pneumonia; severe type (meets any of the following): $\nabla$ Respiratory distress, RR $\geq 30$

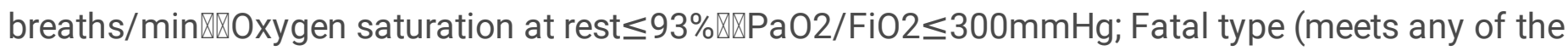

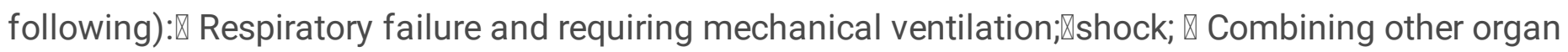
failures requires ICU monitoring and treatment.

\section{Specimen collection}

Blood samples of Group A and Group B were taken within 24-48 hours from admission. Blood tests, Creactive protein, biochemical, coagulation, and myoglobin were tested. The control group collected fasting venous blood for examination on the day of physical exam. 


\section{Major equipment}

The instrument used to detect blood routine is sysmex-XN3000 blood analyzer of Japan Sysmex Corporation, and the reagent is a supporting product of the company; The instrument used to detect CRP is the Jet-iStar 3000 immunoassay analyzer of Zhonghan Shengtai Biotechnology Co., Ltd., and the reagent is a supporting product of the company; The instrument used to detect the coagulation index is CA1500 Hemagglutination Apparatus of Japan Sysmex Corporation, and the reagent is a supporting product of the company; The instrument used to detect myoglobin is Roche 411 , and the reagent is a supporting product of the company.

\section{Statistical processing}

SPSS 31.0 statistical software was used for data processing. Measurement data for normal distributions is expressed as $\pm s$; Comparisons between groups were performed by $t$ test, the test level was $a=0.05$ (both sides); The difference was statistically significant with $\mathrm{P}<0.05$; The measurement data of skewed distribution is expressed as "median (quartile) [M (Q1, Q3)]", and the differences between groups were compared by using the rank sum test. The receiver operating characteristic (ROC) curve were drawn, the area under the ROC curve (AUC) were calculated, and the absolute value of lymphocytes, fibrinogen, myoglobin and other indicators selected to alert the best cutoff value of the COVID-19 and the corresponding sensitivity and specificity.

\section{Results}

\section{Comparison of Group A and Group B's general patient information}

69 cases with COVID-19 pneumonia manifests with chest CT imaging abnormalities, even in asymptomatic patients, with rapid evolution from focal unilateral to diffuse bilateral ground-glass opacities that progressed to or co-existed with consolidations within 1-3 weeks. Combining assessment of imaging features with clinical and laboratory findings could facilitate early diagnosis of COVID-19 pneumonia. were collected in the study, including 2 children, aged 1 year, 7 months and 11 years respectively, and the average age of the remaining 67 patients is 46 years. There are 51 patients in Group A, 29 in males, 18 patients in group B, and 13 in males. There was no significant statistical difference in gender between the two groups ( $\mathrm{P} \otimes 0.05)$. $90 \%$ of the patients in this study had a history of exposure to the Hubei epidemic area, with an incubation period of 2-14 days and the median incubation period of 7.0 days (4.0-10.0). $21.7 \%$ of patients had chronic underlying diseases, of which hypertension and diabetes account for a higher proportion of chronic diseases, and there was no significant statistical difference between the two groups (P凶0.05) (Table 1). 


\section{Differences in patients' clinical symptoms and imaging findings}

$89.9 \%$ of the 69 patients had fever symptoms. There were more fever patients $\left(\varangle 38.5^{\circ} \mathrm{C}\right)$ in Group $\mathrm{B}$, and the duration of fever was longer than that of Group $A$, and the difference was statistically significant (P区 0.05). In addition, cough (75.4\%), chest tightness (63.2\%), and fatigue (59.4\%) were more common symptoms, and a few patients had symptoms of diarrhea (14.5\%), which was more common in Group A. According to the imaging findings, $97.1 \%$ of the patients had lung lesions, among which the cumulative number of lung lobes in Group B was significantly higher than that in Group A(Figure 1), and the difference was statistically significant (Pख0.05); The median time for progression of lesions in COVID-19 pneumonia patients was 3.0 days $(2.0,5.0)$, and there was no significant difference between the two groups (P凶0.05) (Table 2).

\section{Comparison of laboratory indicators for patients}

Among the 69 COVID-19 pneumonia patients, 32 cases of leukocyte abnormalities were seen, of which 21 (30.4\%) cases had decreased white blood cells and 11 (15.9\%) cases had increased white blood cells. A total of $16(23.3 \%)$ patients had an increased neutrophil ratio, and absolute value of lymphocytes decreased in 31 (44.9\%) patients (14 (27.5\%) in Group A and 17 (94.4\%) in Group B). The differences in the above indicators were statistically significant $(P \otimes 0.05)$. C-reactive protein increased in 33 of 69 patients, especially in Group B, and the difference was statistically significant $(P<0.05)$; Abnormal liver function was found in $20(29.0 \%)$ patients (ALT and AST increased in 16 and 12 cases, respectively, with the maximum value of ALT (181 U/L and AST (158 U/L)). Liver function indexes in Group B were higher than those in Group $A$, with statistically significant difference $(P<0.05)$; There were $11(15.9 \%)$ cases of patients with elevated bilirubin, $5(9.8 \%)$ cases in Group A, and $6(33.3 \%)$ cases in Group B. There was no significant statistical difference between the two groups ( $P \bowtie 0.05)$; There were $36(52.2 \%)$ cases of patients with albumin decline. The decrease in albumin in Group B is larger than that in Group A. The difference was statistically significant (Pख0.05); Most patients (89.9\%) had elevated LDH (45 (88.2\%) patients in Group A and 17 (94.4\%) patients in Group B) (Pख0.05); There were only 2 patients with increased renal function; In addition, fibrinogen, D-dimer, and myoglobin were significantly increased in patients of Group B, which is significantly different from Group A (P凶0.05) (Table 3).

\section{Comparison of lymphocyte and myoglobin detection in patients}

Comparing patients in Group A with patients in Group B, the lymphocyte absolute value (L), myoglobin (MB) and fibrinogen (FIB) of COVID-19 pneumonia patients in Group A were significantly higher than that in Group B, with statistically significant differences $(P \leq 0.001)$ (Table 3). Comparing Group A with the 
healthy control group, the absolute value of lymphocytes was significantly higher than that of the healthy control group, with statistically significant difference $(P \otimes 0.001)$ (Table 4)

\section{ROC curve analysis}

Using the data of both Group A and Group B as the receiver operating characteristic (ROC) curve, the data of Group A and Group B patients was compared. The ROC curve was used to evaluate the value of lymphocyte absolute value (L), myoglobin (MB), fibrinogen (FIB) and other indicators in the early warning of severe disease in patients with COVID-19 pneumonia (Figure 2). The optimal truncation values (with maximum Youden index) were selected, and the optimal truncation values of $L, M B$ and FIB were calculated as $1.071^{*} 10^{\wedge} 9 / \mathrm{L}, 37.55 \mathrm{ng} / \mathrm{mL}$ and $4.805 \mathrm{~g} / \mathrm{L}$, respectively. The area under the ROC curve (AUC) was $L$ (0.951), Myo (0.752) and FIB (0.974), respectively. When the optimal truncation value of FIB index was selected, the sensitivity and specificity of severe disease in the early-warning of COVID-19 pneumonia patients were $100 \%$ and $14.0 \%$, respectively, and the sensitivity and specificity were significantly higher than $\mathrm{L}$ and MB (Table 5).

\section{Correlation analysis}

Correlation analysis of the cumulative lung lobes number with L, MB, and FIB in 69 COVID-19 pneumonia patients indicate that the cumulative number of lung lobes in the lesions was positively correlated with $\mathrm{MB}$ and FIB, and negatively correlated with L (Table 6).

\section{Comparison of treatment differences}

$61(88.4 \%)$ patients were treated with oxygen therapy, among which nasal catheter oxygen was the main treatment in Group A, while non-invasive ventilator assisted ventilation or high-flow oxygen were needed for some patients in Group B who were in association with respiratory failure, and the difference was statistically significant (Pख0.05). Only $22(31.9 \%)$ patients were treated with hormone therapy, of which the proportion of Group B was larger, and the time of hormone use was longer than that of Group $A$, and the difference was statistically significant (Pख0.05). The vast majority $(97.1 \%)$ of patients received antiviral treatment immediately after admission, with no statistically significant difference between the two groups (P®0.05) (Table 7). At the same time, we also analyzed the effects of hormone therapy and non-hormonal therapy. Compared with non-hormonal therapy group, hormone therapy did not promote key indicators. (Figure 3)

\section{Discussion}

Current research indicates that SARS-CoV-2 is more than $85 \%$ homologous to bat SARS-like coronavirus (bat-SL-CoVZC45) ${ }^{[5]}$. Therefore, it is considered that COVID-19 was transmitted by bats ${ }^{[6]}$, which needs 
further research confirmation. So far, we are not fully aware of the pathogenesis and the transmission route of the COVID-19 pneumonia ${ }^{[7]}$, so we conducted a retrospective analysis on 69 cases of COVID-19 pneumonia in Suzhou, China.

This study includes 69 cases of COVID-19 diagnosed in the Suzhou Fifth People's Hospital, which shows, similar to Chen's study ${ }^{[8]}$, patients with SARS-CoV-2 were mainly middle-aged and elderly, with a median age of 43 years $(35.5,59.0)$, of which $42(60.9 \%)$ are males. $90 \%$ of the patients had a history of exposure to the Hubei epidemic area, with an incubation period of 2-14 days and the median incubation period of 7.0 days $(4.0-10.0)$, which is also similar to similar to Wang's study ${ }^{[9,10]} .21 .7 \%$ of patients had underlying chronic diseases, of which hypertension and diabetes account for a higher proportion of chronic diseases, and there was no significant statistical difference between the two groups (P凶0.05).

Fever is the most common clinical symptom of the COVID-19 pneumonia, with 62 (89.9\%) cases of the 69 patients observed. Fever occurred in the early stage of the disease, among which 43 (62.3\%) cases had body temperature $\leq 38.5^{\circ} \mathrm{C}$, which was more common in Group A. There were 10 (55.6\%) cases with body temperature $\geq 38.5^{\circ} \mathrm{C}$ in Group B, which was significantly higher than that in Group A, and the difference was statistically significant (Pख0.05). In addition, the duration of fever in Group B was significantly longer than that of Group A, the median time for fever duration in Group B was 7.5 days (4.0-10.5), and the difference was statistically significant (Pख0.05). Cough (75.4\%), chest tightness (63.2\%), and fatigue $(59.4 \%)$ were also common, among which chest tightness was more common in Group B while fatigue was more common in Group $\mathrm{A}$, and the difference was statistically significant ( $\mathrm{P} \otimes 0.05)$. It is considered to be related to lung lobe invasion in severe patients. Diarrhea (14.5\%) and muscle soreness $(10.1 \%)$ were less common in patients, however, we still need to be alert to the patients who are mainly diagnosed with gastrointestinal symptoms, and pay attention to strengthening protection, and conduct SARS-CoV-2 nucleic acid testing timely for patients with a history of epidemiology.

The retrospective analysis of 69 patients with COVID-19 pneumonia indicates that 67 (97.1\%) patients showed lung lesions on imaging, showing multiple sites of distribution, and lesions were seen in both lungs and subpleural area ${ }^{[11]}$, mostly showed grinding glass density shadow, consolidation, interstitial change, small leaf interval thickening ${ }^{[12,13]}$ (Figure 1). The median time from illness onset to lesions progression in COVID-19 pneumonia patients was 3.0 days $(2.0,5.0)$; The median cumulative lung lobes number of lesions was $3.0(3.0,4.0)$, and the cumulative number of lung lobes in Group B was significantly higher than that in Group A, with statistically significant difference (Pख0.05). Laboratory data showed that the WBC, N\%, and CRP of Group B COVID-19 pneumonia patients were significantly higher than those of Group A patients, and the differences were statistically significant (Pख0.05). It is considered to be caused by systemic inflammation which was relatively obvious in severe patients, but the possibility of bacterial infection or secondary fungal infection in some severe patients could not be ruled out. The absolute value of lymphocytes decreased significantly in 45\% of COVID-19 pneumonia patients, especially in the Group B comparing with the Group A, with a statistically significant difference, suggesting that the cellular immune function decreased in early stage in COVID-19 pneumonia patients, especially in severe patients. A total of $20(29.0 \%)$ patients had abnormal liver function (ALT maximum 
value of $181 \mathrm{U} / \mathrm{L}$, AST maximum value of $158 \mathrm{U} / \mathrm{L}$ ). The liver function index of Group B was significantly higher than that of Group $A$, and the difference was statistically significant $(P<0.05)$, suggesting that severe patients are more likely to have liver dysfunction. Most patients had normal renal function, and only $2(2.9 \%)$ had abnormal renal function indicators, both of whom were severe patients, considering that SARS-CoV-2 may not cause significant kidney damage. 36 (52.2\%) patients were associated with hypoproteinemia, and serum albumin (ALB) in Group B was significantly lower than that in Group A, considering that the function of synthetic ALB was decreased caused by liver function damage in severe patients. In addition, the basal metabolic rate and resting energy consumption of severe patients were high, and the ALB catabolic metabolism was accelerated. Therefore, attention should be paid for severe patients to the treatment of albumin supplementation. FIB is a coagulation factor mainly secreted into the blood by the liver cells. It is involved in the blood coagulation process and is a key factor in thrombosis. In addition, FIB is also a stress response protein FIB[ ${ }^{14]}$. A total of 45 (65.2\%) patients had elevated blood FIB content, considering that SARS-CoV-2 infection would lead to stress response of the body, promote the synthesis and release of FIB by liver cells and macrophages, and thereby increase serum. In addition, FIB in Group B was significantly higher than that in Group A, with statistically significant difference (P区 0.05). It is considered to be caused by systemic inflammation which was relatively obvious in severe patients. D-dimer is a product of fibrinolytic cross-linked fibrin clot formation. Elevated D-dimer levels indicate high blood clotting and are a sensitive marker of acute thrombosis. This study shows that the value of D-dimer in Group B was significantly higher than that in Group A, with statistically significant difference (Pख0.05). It is considered that harmful substances such as viruses and endotoxins can activate coagulation factor XII after entering the blood, activate the endogenous coagulation system, and activate the fibrinolytic system, which leads to an increase in D-dimer. Severe patients often have systemic inflammation, which could cause endothelial function to be impaired, resulting in platelet aggregation, release of coagulation factors, thereby leading to hyperfunction of the fibrinolytic system. The increase of FIB and D-dimer indicates that preventive anticoagulation therapy should be given to COVID-19 pneumonia patients, especially for severe patients.

Treatment results indicate that 61 (88.4\%) patients were treated with oxygen therapy, among which nasal catheter oxygen was the main treatment (43 (84.3\%) cases in Group A, $5(27.8 \%)$ cases in Group B). Some patients in Group B were associated with respiratory failure, thus non-invasive ventilator assisted ventilation or high-flow oxygen were needed, and the difference was statistically significant (P凶0.05). The vast majority $(97.1 \%)$ of patients received antiviral treatment immediately after admission, while only 22 (31.9\%) patients were treated with hormone therapy, most of whom were from Group B, also the time of hormone use was significantly longer than that of Group A, and the difference was statistically significant $(\mathrm{P} \llbracket 0.05)$.

In this study, L, MB and FIB were selected as meaningful laboratory indicators to help distinguish between general and severe classification. The results showed that the values of $L, M B$, and FIB in the Group $B$ were significantly different from those in the Group $A$, and the difference was statistically significant (P区 0.05). When FIB takes a critical value of $4.805 \mathrm{~g} / \mathrm{L}$, the sensitivity and specificity are $100 \%$ and $14 \%$, respectively, which are significantly better than $L$ and MB. It can be seen from the ROC chart that FIB has 
the largest area under the ROC curve (0.974), indicating that FIB could be used as an effective laboratory indicator to help distinguish general and severe classification, but the specificity of FIB is low. Therefore, a comprehensive diagnosis should be made based on clinical manifestations and influence data. For patients with chest tightness, $L<1.071^{*} 10^{\wedge} 9 / \mathrm{L}$, and FIB significantly higher than $4.9065 \mathrm{~g} / \mathrm{L}$, we should be alert to the possibility that they may subsequently progress into severe or severe tendency, which will help timely clinical judgement of the condition and adjustment of treatment.

Our study has some limitations. This study did not cover all the COVID-19 cases in our hospital; some patients were excluded but were not diagnosed; the number of selected cases was relatively small; there might be bias factors in case selection; findings of statistical tests and $p$ values should be interpreted with caution, and non-significant $p$ values do not necessarily rule out the difference between Group $A$ and Group B patients. In addition, the patient's discomfort symptoms are highly subjective, and there might be errors in clinical symptoms. Some patients did not seek medical treatment in time, and the imaging performance was lagging. Therefore, further researches are needed to get a full picture of the COVID-19 pneumonia.

\section{Conclusions}

This study is about the retrospective analysis of the 69 COVID-19 pneumonia cases. In addition to the epidemiological findings that the majority of the patients with SARS-CoV-2 are middle-aged and elderly, with more men than women, patients having underlying diseases are more susceptible and most patients had a history of exposure to the Hubei epidemic area, respiratory symptoms such as fever, cough, chest tightness are the main symptoms, we find clinical features for severe patients such as higher fever peaks, longer fever duration and more lung lesions. We also find lymphocyte counts decreased, myoglobin and fibrinogen increased in severe patients. Further analysis indicates that fibrinogen indicator is better than indicators of lymphocyte and myoglobin in respect of distinguishing general and severe patients, from both the sensitivity and specificity perspective. This study further specifies the clinical characteristics of the COVID-19 pneumonia patients and certain more meaningful laboratory indicators for disease progression.

\section{Declarations}

Ethics approval and consent to participatel: All procedures performed in studies involving human participants were in accordance with the ethical standards of the institutional and/or national research committee and with the 1964 Helsinki declaration and its later amendments or comparable ethical standards.

Consent for publication: Not applicable.

Availability of data and materials: The datasets used and/or analysed during the current study are available from the corresponding author on reasonable request. 
Competing interests: The authors declare that they have no competing interests.

Funding: This study was supported by grants from the Science and Technology Plan of Suzhou, China (SYS201778םSS201880ロSYS2018096 and SS2019010);Social Development Project of Jiangsu Provincial Department of Science and Technology (BE2019673); High-level Health Talents in Jiangsu Province (LGY2019014);

Authors' contributions: YW, XY, JCX and MYW conceived and designed the study. YW, LY and JCX contributed to the literature search. YW, LY and XY contributed to data collection. YW JCX and XY contributed to data analysis. XY and MYW contributed to data interpretation. YW and JCX contributed to the figures. JPZ, XHS, PJT, ZJY, and MYW contributed to writing of the report.

Acknowledgements: We thank all patients, clinicians, and support staff who participated in this study.

\section{References}

[1] Thompson RN. Novel Coronavirus Outbreak in Wuhan, China, 2020: Intense Surveillance Is Vital for Preventing Sustained Transmission in New Locations. J Clin Med. 2020; 9(2); doi: 10.3390/jcm9020498..

[2] Guan W, Xian J. The progress of 2019 novel coronavirus event in China. J Med Virol. 2020; doi: 10.1002/jmv.25705.

[3] Wu A, Peng Y, Huang B, Ding X, Wang X, Niu P, Meng J, Zhu Z, Zhang Z, Wang J, Sheng J, Quan L, Xia Z, Tan W, Cheng G, Jiang. Genome Composition and Divergence of the Novel Coronavirus (2019nCoV) Originating in China. Cell Host Microbe 2020; doi: 10.1016/j.chom.2020.02.001 .

[4] Tian X, Li C, Huang A, Xia S, Lu S, Shi Z, Lu L, Jiang S, Yang Z, Wu Y, Ying T. Potent binding of 2019 novel coronavirus spike protein by a SARS coronavirus-specific human monoclonal antibody. Emerg Microbes Infect. 2020; 9(1):382-385; doi: 10.1080/22221751.2020.1729069..

[5] Liu J, Zheng X, Tong Q, Li W, Wang B, Sutter K, Trilling M, Lu M, Dittmer U, Yang D. Overlapping and discrete aspects of the pathology and pathogenesis of the emerging human pathogenic coronaviruses SARS-CoV, MERS-CoV, and SARS-CoV-2. J Med Virol 2020; doi: 10.1002/jmv.25709.

[6] Wassenaar TM, Zou Y. 2019_nCoV: Rapid classification of betacoronaviruses and identification of traditional Chinese medicine as potential origin of zoonotic coronaviruses. Lett Appl Microbiol 2020; doi: 10.1111/lam.13285.

[7] Lu H, Stratton CW, Tang YW. Outbreak of pneumonia of unknown etiology in Wuhan, China: The mystery and the miracle. J Med Virol. 2020;92(4):401-402; doi: 10.1002/jmv.25678.

[8] Chen N, Zhou M, Dong X, Qu J, Gong F, Han Y, Qiu Y, Wang J, Liu Y, Wei Y, Xia J, Yu T, Zhang X, Zhang L. Epidemiological and clinical characteristics of 99 cases of 2019 novel coronavirus pneumonia 
in Wuhan, China: a descriptive study. Lancet. 2020; 395(10223):507-513; doi: 10.1016/S01406736(20)30211-7.

[9] Linton NM, Kobayashi T, Yang Y, Hayashi K, Akhmetzhanov AR, Jung SM, Yuan B, Kinoshita R, Nishiura H. Incubation Period and Other Epidemiological Characteristics of 2019 Novel Coronavirus Infections with Right Truncation: A Statistical Analysis of Publicly Available Case Data. J Clin Med. 2020; 9(2); doi: 10.3390/jcm9020538..

[10] Wang D, Hu B, Hu C, Zhu F, Liu X, Zhang J, Wang B, Xiang H, Cheng Z, Xiong Y, Zhao Y, Li Y, Wang X, Peng Z. Clinical Characteristics of 138 Hospitalized Patients With 2019 Novel Coronavirus-Infected Pneumonia in Wuhan, China. JAMA. 2020; doi: 10.1001/jama.2020.1585 .

[11] Xu X, Yu C, Qu J, Zhang L, Jiang S, Huang D, Chen B, Zhang Z, Guan W, Ling Z, Jiang R, Hu T, Ding Y, Lin L, Gan Q, Luo L, Tang X, Liu J. Imaging and clinical features of patients with 2019 novel coronavirus SARS-CoV-2. Eur J Nucl Med Mol Imaging. 2020; doi: 10.1007/s00259-020-04735-9.

[12] Shi H, Han X, Jiang N, Cao Y, Alwalid O, Gu J, Fan Y, Zheng C. Radiological findings from 81 patients with COVID-19 pneumonia in Wuhan, China: a descriptive study. Lancet Infect Dis. 2020; doi: 10.1016/S1473-3099(20)30086-4.

[13] Feng K, Yun YX, Wang XF, Yang GD, Zheng YJ, Lin CM, Wang LF. Analysis of CT features of 15 Children with 2019 novel coronavirus infection. Zhonghua Er Ke Za Zhi. 2020;58(0):E007;doi: 10.3760/cma.j.issn.0578-1310.2020.0007.

[14] Yang $\mathrm{Y}$, Tang $\mathrm{H}$. Aberrant coagulation causes a hyper-inflammatory response in severe influenza pneumonia. Cell Mol Immunol. 2016;13(4):432-42; doi: 10.1038/cmi.2016.1.

\section{Tables}

Table1. Comparison of general patient information ([M( $\left.\left.Q_{1} \square Q_{3}\right)\right]$ )

\begin{tabular}{l|c|c|c|c}
\hline $\begin{array}{c}\text { Group } \\
\text { Characteristics }\end{array}$ & $\begin{array}{c}\text { All patients } \\
(\mathrm{n}=69)\end{array}$ & $\begin{array}{c}\text { Group A } \\
(\mathrm{n}=51)\end{array}$ & $\begin{array}{c}\text { Group B } \\
(\mathrm{n}=18)\end{array}$ & $\mathrm{P}$ \\
\hline Age[years, $\left.M\left(Q_{1} \square Q_{3}\right)\right]$ & $43.0(35.5,59.0)$ & $41.0(35.0,57.0)$ & $46.0(37.3,60.3)$ & 0.256 \\
\hline Sex & - & - & - & 0.396 \\
\hline Men & $42(60.9 \%)$ & $29(56.9 \%)$ & $13(72.2 \%)$ & - \\
\hline Women & $27(39.1 \%)$ & $22(43.1 \%)$ & $5(27.8 \%)$ & - \\
\hline Exposure to the Hubei epidemic area & $62(89.9 \%)$ & $45(88.2 \%)$ & $17(94.4 \%)$ & 0.456 \\
\hline Incubation period (days) & $7(4,10)$ & $7.0(5,10)$ & $6.5(4,10)$ & 0.665 \\
\hline Comorbidity & $15(21.7 \%)$ & $12(23.5 \%)$ & $3(16.7 \%)$ & 0.264 \\
\hline Hypertension & $4(5.8 \%)$ & $4(7.8 \%)$ & 0 & - \\
\hline Diabetes & $4(5.8 \%)$ & $2(3.9 \%)$ & $2(11.1 \%)$ & - \\
\hline Respiratory diseases & $1(1.4 \%)$ & $1(2.0 \%)$ & 0 & - \\
\hline Chronic liver disease & $3(4.3 \%)$ & $3(5.9 \%)$ & 0 & - \\
\hline Chronic kidney disease & $2(2.9 \%)$ & $2(3.9 \%)$ & 0 & - \\
\hline Malignancy & $2(2.9 \%)$ & $2(3.9 \%)$ & 0 & - \\
\hline Other diseases & $3(4.3 \%)$ & $2(3.9 \%)$ & $1(5.6 \%)$ & - \\
\hline
\end{tabular}


Table 2. Differences in patients' clinical symptoms and imaging findings

\begin{tabular}{|c|c|c|c|c|}
\hline $\begin{array}{c}\text { Group } \\
\text { Characteristics } \\
\end{array}$ & $\begin{array}{l}\text { All patients } \\
(\mathrm{n}=69)\end{array}$ & $\begin{array}{l}\text { Group A } \\
(\mathrm{n}=51)\end{array}$ & $\begin{array}{l}\text { Group B } \\
(\mathrm{n}=18)\end{array}$ & $\mathrm{P}$ \\
\hline \multicolumn{5}{|l|}{ Clinical symptoms on admission } \\
\hline Fever & $62(89.9 \%)$ & $44(86.3 \%)$ & $18(100 \%)$ & 0.100 \\
\hline $\mathrm{T} \leq 38.5^{\circ} \mathrm{C}$ & $43(62.3 \%)$ & $35(68.6 \%)$ & $8(44.4 \%)$ & \multirow[b]{2}{*}{0.008} \\
\hline $\mathrm{T} \square 38.5^{\circ} \mathrm{C}$ & $19(27.5 \%)$ & $9(17.6 \%)$ & $10(55.6 \%)$ & \\
\hline Fever duration (days) & $\begin{array}{c}5.0 \\
(2.0,9.0) \\
\end{array}$ & $\begin{array}{c}4.0 \\
(1.0,9.0)\end{array}$ & $\begin{array}{c}7.5 \\
(4.0,10.5) \\
\end{array}$ & 0.031 \\
\hline Cough & $52(75.4 \%)$ & $36(70.6 \%)$ & $16(88.9 \%)$ & 0.124 \\
\hline Chest tightness & $12(63.2 \%)$ & $2(3.9 \%)$ & $10(55.6 \%)$ & $\square 0.01$ \\
\hline Fatigue & $41(59.4 \%)$ & $24(47.2)$ & $17(94.4 \%)$ & $\square 0.01$ \\
\hline Diarrhea & $10(14.5 \%)$ & $9(17.6)$ & $1(5.6 \%)$ & 0.239 \\
\hline Muscle soreness & $7(10.1 \%)$ & $3(5.9 \%)$ & $4(22.2 \%)$ & 0.040 \\
\hline \multicolumn{5}{|l|}{ Imaging findings } \\
\hline No lung lesion & $2(2.9 \%)$ & $2(3.9 \%)$ & 0 & \multirow[t]{2}{*}{0.397} \\
\hline Lung lesions & $67(97.1 \%)$ & $49(96.1 \%)$ & $18(100 \%)$ & \\
\hline $\begin{array}{l}\text { Total number of lung fields in the lesion ( } 2 \text { lung fields on the left and } 3 \text { lung fields on the } \\
\text { right) }\end{array}$ & $\begin{array}{c}3.0(3.0 \square \\
4.0)\end{array}$ & $\begin{array}{c}3.0 \\
(2.0,4.0) \\
\end{array}$ & $4.5(4.0,5.0)$ & $\square 0.01$ \\
\hline Days for illness lesion progression & $\begin{array}{c}3.0 \\
(2.0,5.0)\end{array}$ & $\begin{array}{c}3.0(1.5- \\
5.0)\end{array}$ & $3.0(2.0,5.0)$ & 0.694 \\
\hline
\end{tabular}

Table 3. Comparison of laboratory indicators for patients 


\begin{tabular}{|c|c|c|c|c|}
\hline $\begin{array}{l}\text { Group } \\
\text { Laboratory indicators }\end{array}$ & $\begin{array}{l}\text { All patients } \\
(\mathrm{n}=69)\end{array}$ & $\begin{array}{c}\text { Group A } \\
(\mathrm{n}=51)\end{array}$ & $\begin{array}{c}\text { Group B } \\
(\mathrm{n}=18)\end{array}$ & $\mathrm{P}$ \\
\hline WBC $\left(* 10^{\wedge} 9 / \mathrm{L}\right.$, normal value $\left.3.5-9.5\right)$ & $4.5(3.4,6.5)$ & $4.4(3.3,6.0)$ & $6.2(4.0,10.5)$ & 0.017 \\
\hline$\square 3.5$ & $21(30.4 \%)$ & $18(35.3 \%)$ & $3(16.7 \%)$ & - \\
\hline$\square 9.5$ & $11(15.9 \%)$ & $3(5.9 \%)$ & $8(44.4 \%)$ & - \\
\hline N\% (normal value 40-75) & $69.0(53.6,74.0)$ & $58.0(49.5,67.6)$ & $79.2(71.5,87.1)$ & $\square 0.001$ \\
\hline$\square 40$ & $3(4.3 \%)$ & $2(3.9 \%)$ & $1(5.6 \%)$ & - \\
\hline$\square 75$ & $16(23.3 \%)$ & $4(7.8 \%)$ & $12(66.7 \%)$ & - \\
\hline $\mathrm{L}\left(* 10^{\wedge} 9 / \mathrm{L}\right.$, normal value $\left.1.1-3.2\right)$ & $1.1(0.8,1.5)$ & $1.2(1.1,1.6)$ & $0.7(0.6,0.8)$ & $\square 0.001$ \\
\hline$\square 1.1$ & $31(44.9 \%)$ & $14(27.5 \%)$ & $17(94.4 \%)$ & - \\
\hline$\square 3.2$ & $2(2.9 \%)$ & $2(3.9 \%)$ & 0 & - \\
\hline CRP (mg/L, normal value 10 ) & $8.7(1.8,22.1)$ & $6.6(\square 0.5,18.1)$ & $24.6(6.7,45.5)$ & 0.001 \\
\hline$\square 10$ & $33(47.8 \%)$ & $20(39.2 \%)$ & $13(72.2 \%)$ & - \\
\hline TB (umol/L, normal value 4.0-17.1) & $9.6(6.6,14.4)$ & $9.0(6.5,12.6)$ & $12.4(6.5,23.7)$ & 0.121 \\
\hline$\square 4.0$ & $2(2.9 \%)$ & $2(3.9 \%)$ & 0 & - \\
\hline$\square 17.1$ & $11(15.9 \%)$ & $5(9.8 \%)$ & $6(33.3 \%)$ & - \\
\hline AST (U/L, normal value 8-40) & $27.0(21.0,34.0)$ & $24.0(21.0,32.0)$ & $33.0(25.0,49.5)$ & 0.017 \\
\hline$\square 40$ & $12(17.4 \%)$ & $6(8.7 \%)$ & $6(8.7 \%)$ & - \\
\hline ALT (U/L, normal value 5-40) & $29.0(23.5,39.5)$ & $28.0(23.0,36.0)$ & $37.0(25.5 \square 66.0)$ & 0.015 \\
\hline$\square 40$ & $16(23.2 \%)$ & $8(15.7 \%)$ & $8(44.4 \%)$ & - \\
\hline Albumin (g/L口normal value38-55) & $37.8(33.7,39.8)$ & $38.4(36.8,40.1)$ & $32.7(31.4,36.0)$ & $\square 0.001$ \\
\hline$\square 38$ & $36(52.2 \%)$ & $20(39.2 \%)$ & $16(88.9 \%)$ & \\
\hline LDH (U/L, normal value135-225) & $426.0(349.5,554.0)$ & $423.0(337.0,514.0)$ & $532.5(419.0,950.3)$ & 0.005 \\
\hline$\square 225$ & $62(89.9 \%)$ & $45(88.2 \%)$ & $17(94.4 \%)$ & - \\
\hline Cr (umol/L, normal value44-106) & $65.0(53.6,82.6)$ & $64.9(52.3,86.3)$ & $66.1(56.4,78.9)$ & 0.946 \\
\hline$\square 44$ & 0 & 0 & 0 & - \\
\hline$\square 106$ & $2(2.9 \%)$ & 0 & $2(11.1 \%)$ & - \\
\hline MB (ng/mL, normal value25-58) & $24.2(<21.0,39.1)$ & $<21.0(<21.0,32.6)$ & $41.3(23.2,79.1)$ & 0.001 \\
\hline$\square 25$ & $37(53.6 \%)$ & $31(60.8 \%)$ & $6(33.3 \%)$ & - \\
\hline$\square 58$ & $8(11.6 \%)$ & $3(5.9 \%)$ & $5(27.8 \%)$ & - \\
\hline FIB (g/L】normal value2-4) & $4.5(3.6,5.4)$ & $4.1(3.1,4.6)$ & $6.4(5.6,7.2)$ & $\square 0.001$ \\
\hline$\square 4$ & $45(65.2 \%)$ & $27(52.9 \%)$ & $18(100 \%)$ & - \\
\hline D-dimer (ug/L】normal value0-550) & $220(160,375)$ & $200(140,270)$ & $375(235,870)$ & 0.001 \\
\hline$\square 550$ & $10(14.5 \%)$ & $\begin{array}{l}2(2.9 \%) \\
1 .\end{array}$ & $\%)$ & - \\
\hline
\end{tabular}

Table 4. Comparison of lymphocyte and myoglobin detection in patients

\begin{tabular}{l|c|c|c}
\hline \multicolumn{1}{c|}{ Indicators } & $\mathrm{L}\left(* 10^{\wedge} 9\right)$ & $\mathrm{MB}$ & FIB \\
Group & & & \\
\hline Group A (n=51) & $1.23^{\mathrm{a}}(1.09,1.63)$ & $\square 21^{\mathrm{a}}(\square 21,32.57)$ & $4.11^{\mathrm{a}}(3.10,4.58)$ \\
\hline Group B $(\mathrm{n}=18)$ & $0.71(0.55,0.81)$ & $41.27(23.24,79.10)$ & $6.42(5.60,7.20)$ \\
\hline Healthy control group $(\mathrm{n}=20)$ & $1.96^{\mathrm{b}}(1.48,2.35)$ & - & - \\
\hline
\end{tabular}

Note: comparing with Group B, ${ }^{a} p \llbracket 0.001$ for indicators in Group A, ${ }^{b} p \llbracket 0.001$ for indicator of L in healthy control group

Table 5. Comparison of AUC, truncation value, sensitivity, and specificity of 3 indicators 


\begin{tabular}{lllllllrr}
\hline Indicator & AUC & $\begin{array}{l}\text { Diagnostic } \\
\text { threshold }\end{array}$ & $\begin{array}{l}\text { Sensitivity } \\
(\%)\end{array}$ & $\begin{array}{l}\text { Specificity } \\
(\%)\end{array}$ & $\begin{array}{l}95 \% \\
\text { interval }^{\mathrm{b}}\end{array}$ & $\begin{array}{l}\text { confidence } \\
\text { Standard } \\
\text { error }\end{array}$ & $\begin{array}{l}\text { Significance level P (area = } \\
0.5)\end{array}$ \\
\hline $\mathrm{L}$ & 0.951 & $1.071 * 10^{\wedge} 9 / \mathrm{L}$ & 94.10 & & 12.00 & $0.890-1.000$ & 0.031 \\
$\mathrm{MB}$ & 0.752 & $37.55 \mathrm{ng} / \mathrm{mL}$ & 58.80 & 14.00 & $0.617-0.887$ & 0.069 \\
$\mathrm{FIB}$ & 0.974 & $4.805 \mathrm{~g} / \mathrm{L}$ & 100 & 14.00 & $0.943-1.000$ & 0.016 & 0.0001 \\
\hline
\end{tabular}

Table 6. Correlation of cumulative lung field number with L, MB, and FIB indexes

\begin{tabular}{ccc}
\hline Parameter & Pearson Correlation coefficient & $P$ value \\
\hline L & -0.313 & 0.010 \\
MB & 0.321 & 0.009 \\
FIB & 0.557 & $\square 0.001$ \\
\hline
\end{tabular}

Table 7. Comparison of treatment differences

\begin{tabular}{l|c|c|c|c}
\hline $\begin{array}{c}\text { Group } \\
\text { Treatment }\end{array}$ & $\begin{array}{c}\text { All patients } \\
(\mathrm{n}=69)\end{array}$ & $\begin{array}{c}\text { Group A } \\
(\mathrm{n}=51)\end{array}$ & $\begin{array}{c}\text { Group B } \\
(\mathrm{n}=18)\end{array}$ & $\mathrm{P}$ \\
\hline Oxygen therapy & $61(88.4 \%)$ & $43(84.3 \%)$ & $18(100 \%)$ & 0.044 \\
\hline Nasal catheter oxygen & $48(69.6 \%)$ & $43(84.3 \%)$ & $5(27.8 \%)$ & - \\
\hline \multicolumn{1}{c}{ Mask oxygen } & $7(10.1 \%)$ & 0 & $7(38.9 \%)$ & - \\
\hline High flow oxygen & $3(4.3)$ & 0 & $3(16.7 \%)$ & - \\
\hline Non-invasive ventilator & $2(2.9 \%)$ & 0 & $2(11.1 \%)$ & - \\
\hline Hormone therapy & $22(31.9 \%)$ & $6(11.8 \%)$ & $16(88.9 \%)$ & $\square 0.001$ \\
\hline Hormone using time & $7(5,9)$ & $6(4.5,9.25)$ & $7(5,9)$ & $<0.001$ \\
\hline Antiviral therapy & $67(97.1 \%)$ & $49(96.1 \%)$ & $18(100 \%)$ & 0.397 \\
\hline
\end{tabular}

\section{Figures}



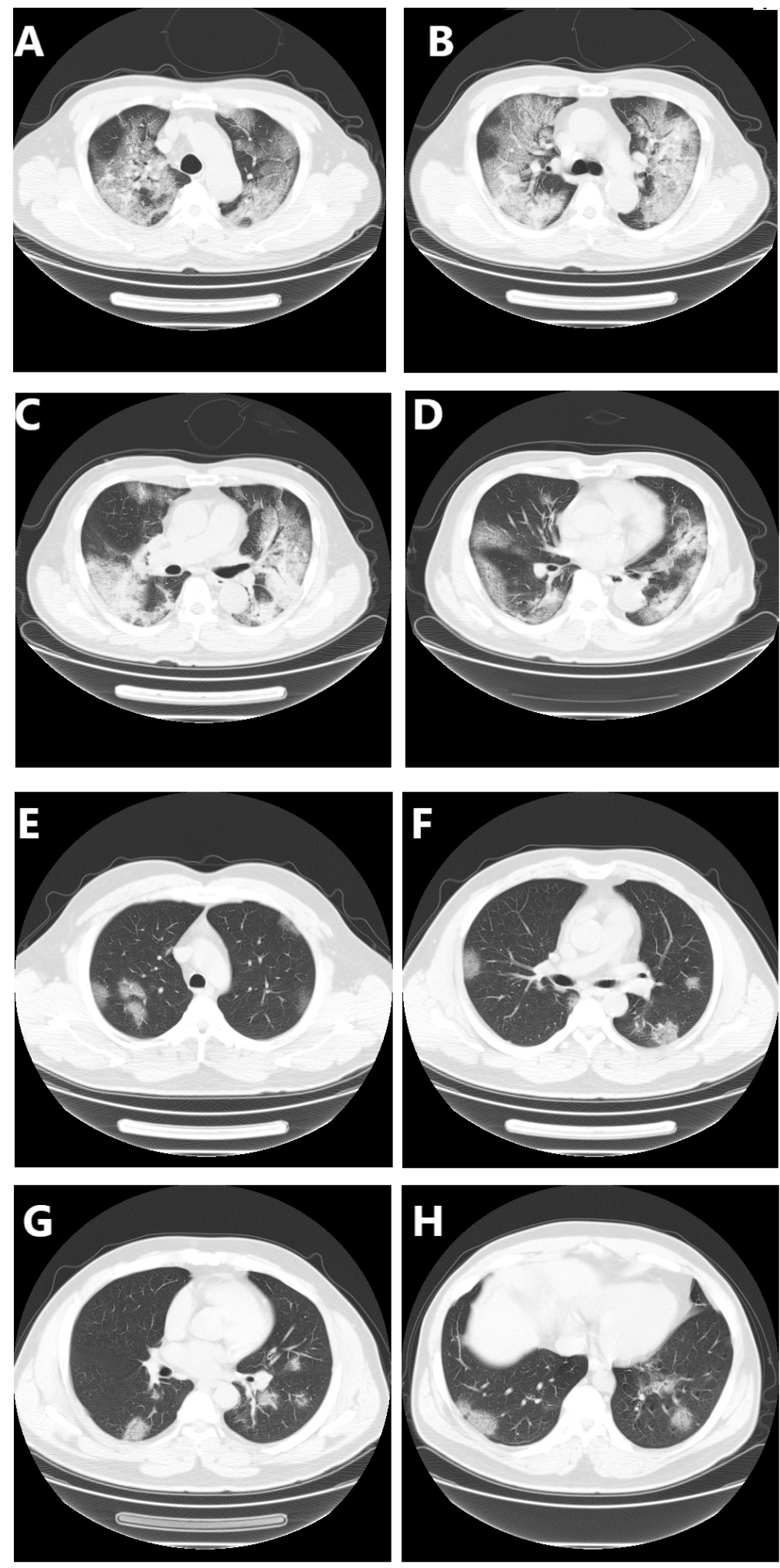

Figure 2

CT results of COVID-19 pneumonia patients. (A-D) CT results of severe patient;(E-G) CT results of general patient 


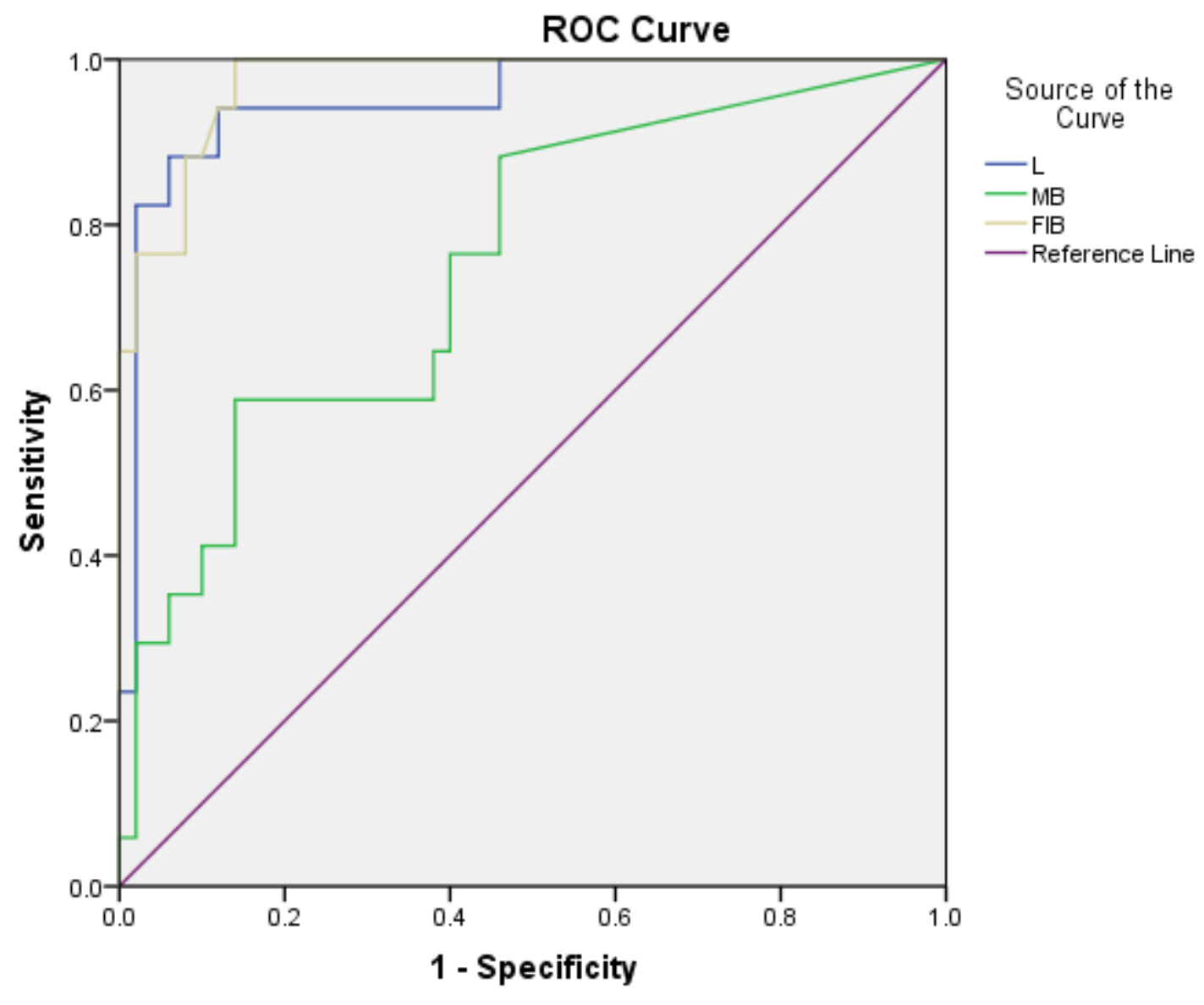

Diagonal segments are produced by ties.

Figure 4

ROC curve of lymphocyte absolute value (L), myoglobin (MB), fibrinogen (FIB) 

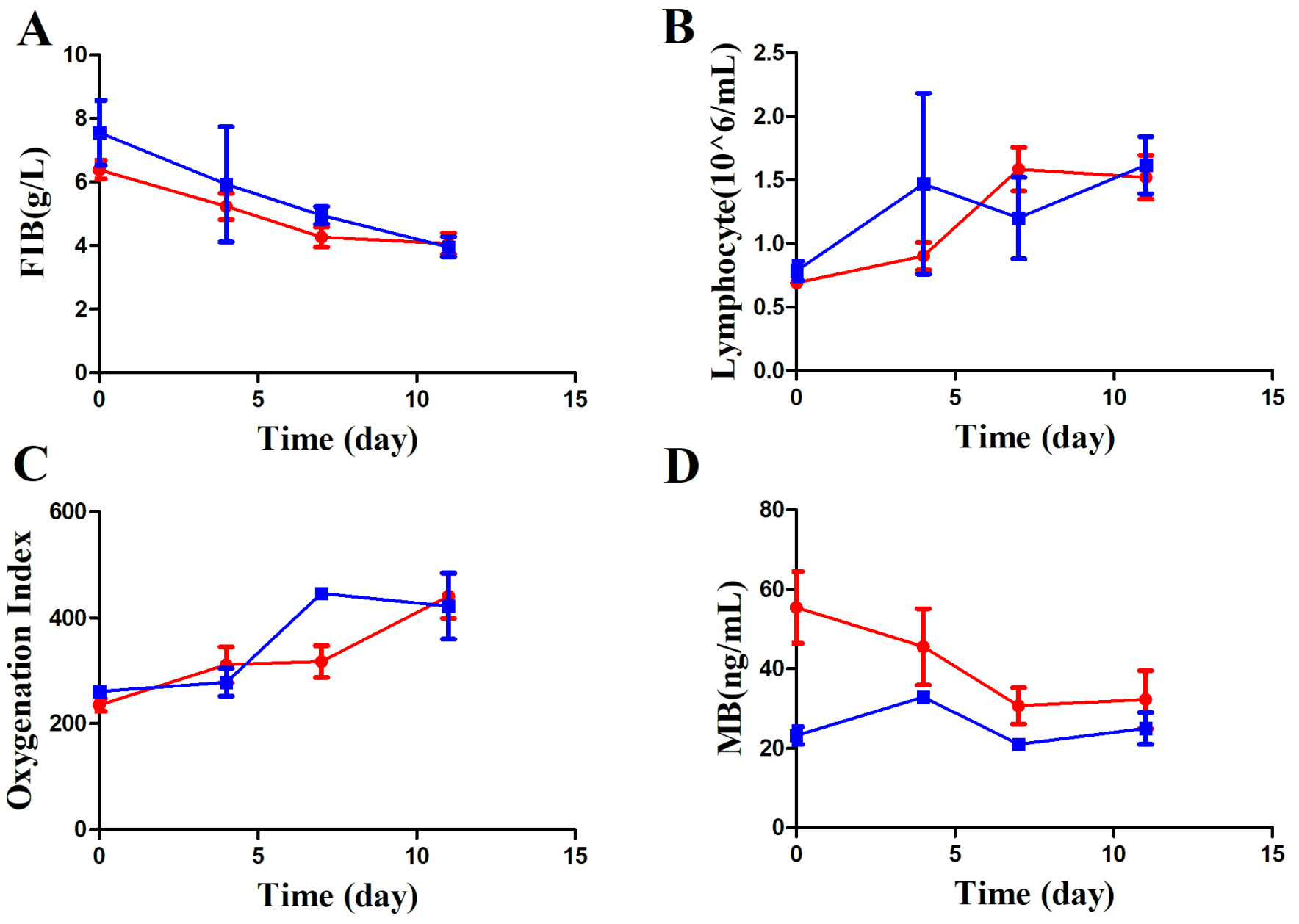

Figure 6

Effect of hormone therapy on oxygenation index, Lymphocyte, MB and FIB. (A) Effect of hormone therapy on FIB; (B) Effect of hormone therapy on Lymphocyte; (C) Effect of hormone therapy on oxygenation index; (D) Effect of hormone therapy on MB. Red: Hormone therapy group, Blue: Non-hormonal treatment group

\section{Supplementary Files}

This is a list of supplementary files associated with this preprint. Click to download.

- Supplementary.docx

- Supplementary.docx 